\title{
Public opinions on seven different stray cat population management scenarios in Flanders, Belgium
}

\author{
Ciska De Ruyver ${ }^{\text {a, }}$, Emmanuel Abatih ${ }^{\mathrm{b}}$, Paolo Dalla Villa ${ }^{\mathrm{c}}$, Els H.K.A. Peeters ${ }^{\mathrm{d}}$, \\ Jane Clements ${ }^{\mathrm{e}}$, Agnes Dufau ${ }^{\mathrm{f}}$, Christel P.H. Moons ${ }^{\mathrm{a}}$ \\ ${ }^{a}$ Department Nutrition, Genetics and Ethology, Ethology and Animal Welfare Research Group, Faculty of Veterinary Medicine, Ghent University, Heidestraat 19, 9820 \\ Merelbeke, Belgium \\ b Department of Applied Mathematics, Computer Sciences and Statistics, Ghent University, Krijgslaan 281-S9, 9000 Gent, Belgium \\ ${ }^{\mathrm{c}}$ World Organization for Animal Health - OIE Sub-Regional Representation in Brussels, Boulevard du Jardin Botanique 55, 1000 Bruxelles, Belgium \\ d Department of Agro- and Biotechnology, SALTO Research Core - Behavioral Biology and Animal Welfare, Faculty of Industrial Sciences and Technology, Odisee \\ University of Applied Sciences, Hospitaalstraat 23, 9100 Sint-Niklaas, Belgium \\ ${ }^{\mathrm{e}}$ Cats Protection, Lewes Rd, Chelwood Gate, Haywards Heath RH17 7TT, United Kingdom \\ ${ }^{\mathrm{f}}$ FdCATS expertos comprometidos con el bienestar felino, 14001 Cordoba, Spain
}

\section{A R T I C L E I N F O}

\section{Keywords:}

Feline

Stray cats

Overpopulation

Cat population management

Survey

Public opinion

Socio-demographic factors

Area of residence

Responsible household cat ownership

Managed community cats

\begin{abstract}
A B S T R A C T
Stray cat population management is an important worldwide issue. Understanding citizen attitudes towards stray cat control options is vital to the success of controlling stray cat numbers, as public perception affects the acceptance of, support for and collaboration in stray cat management policies. Audience segmentation, as to enable each group to be engaged in the stray cat management policy, is important for the success of the interventions. Therefore a web-based survey was conducted among Flemish citizens in order to examine differences in acceptance towards seven management scenarios: household cat neutering with financial support for the owner, household cat neutering without financial support for the owner, encouraging responsible household cat ownership, trapping stray cats and taking them to a shelter, trapping and neutering stray cats for release into a managed "cat colony" (composed by so called "community cats"), trapping and killing of stray cats, and undertaking no action. A total of 4059 valid responses were collected and the proportions of agreement were compared across the different management scenarios using the two-sample z-test. Interactions among factors that influenced each management scenario were investigated using the CHAID (Chi-squared Automatic Interaction Detection) analysis and visualized on a tree.

Our results showed that fostering responsible household cat ownership (89.9\%) and conversion of stray cats to "community cats" (76.3\%) were most supported by respondents in our sample (which consisted mainly of females, cat-lovers, and families without children). Least supported were the killing of stray cats (7.7\%) and undertaking no action (3.3\%). The demographic analyses revealed that for the acceptance of management scenarios there were three important factors (attitude towards cats, area of residence, and gender), two weaker factors (education and having children) and two which had almost no impact (age and cat ownership). We propose that future studies should focus on the effect of 'area of residence', 'having children' and 'education'.

In conclusion, our research confirms that management of and communication on stray cat strategies should not be developed with a one-size-fits-all approach. Efforts should be tailored to each audience segment, thus adapted to the area of residence and human characteristics.
\end{abstract}

\section{Introduction}

Household cats, Felis sylvestris catus, are currently among the most popular pets in the Western world (Carvelli et al., 2016; Downes et al.,
2013; Kuhne, 2019). In 2018, 20 million European households and 32 million US households owned at least one cat (American Veterinary Medical Association, 2018; European pet food industry 2019). Lost or abandoned household cats are seen as a major contributing source to the

\footnotetext{
* Corresponding author.

E-mail address: ciska.deruyver@ugent.be (C. De Ruyver).
} 
stray cat population (Dalla Villa et al., 2019; Finkler and Terkel, 2012; Murray et al., 2015; Welsh et al., 2014). We determine the term "stray cat" by combining elements of the two categories "stray cats" and "feral cats" from the International Society of Feline Medicine (ISFM) Guidelines on Population Management and Welfare of Unowned Domestic Cats. Our definitions were derived from those of the IFSM and adaptations were made because of the situation in Flanders. In Flanders, the public makes no real distinction between feral and stray cats because it is almost impossible for them to make a distinction between feral and stray cats. Furthermore, in Dutch no clear defined denominators are available for "feral" or "stray": all unowned cats are referred to as "zwerfkatten", regardless of their background. In addition, in Flemish Animal welfare legislation "community cats" form a category according to the legal regulations. Stray and feral cats become "community cats" once the community takes full responsibility of their welfare, and they live in managed cat colonies. Stray and feral cats living in non-managed colonies will become community cats once the TNR program is implemented. Therefore, for the purpose of this study, we accordingly defined the categories in the survey as:

- "Stray" cats are unowned cats that are uncared for and not neutered

- "Community" cats are unowned cats that are neutered and cared for by (certified) feeders or caretakers. They do not include any household pets that occasionally go and eat there too.

- "Household" cats are owned cats that are included in your household. They get water, food, shelter and veterinary treatment when necessary. "Household" cats also include cats that are "adopted" and may previously have been stray or owned by another household. Pedigree cats kept for breeding are not household cats.

Reported or presumed problems and concerns involving stray cats are associated with poor health and welfare, nuisance for the human population and possible impact on ecosystems (Gilhofer et al., 2019; Gunther et al., 2018, 2015; Slater, 2004; Uetake et al., 2014). Nuisance caused by stray cats (for example, faeces in the garden, scratched bin bags, vocalisations during mating time) is an important problem for citizens in urban environments (Bjerke and Østdahl, 2004; Dabritz et al., 2006). In addition, financial implications of managing these populations are not negligible (Stavisky et al., 2012). Research shows that the number of stray cats depends on human population density, human behaviour (pet owners), and the reproductive potential (Aguilar and Farnworth, 2013; Flockhart et al., 2016; Liberg and Sandell, 2000; Stavisky, 2014). How household cat owners take responsibility for their animals and municipalities for stray cats is progressively being legislated in different countries and is no longer purely a case of individual decisions (Finkler and Terkel, 2012; Høgåsen et al., 2013; International Cat Care, 2018; Natoli et al., 2006, 2019; The European Parliament's Intergroup on the Welfare and Conservation of Animals, 2016). There is a need for governments to implement policies to control the stray cat population, but the question is how to do this (Calver et al., 2020; Crawford and Fleming, 2019; Peterson et al., 2012; Wolf and Schaffner, 2019).

Controlling stray cat populations can be done with indirect interventions via the household cat population, e.g., neutering of household cats or fostering responsible household cat ownership, (Davey and Zhao, 2020; Kuhne, 2019; RSPCA, 2014) and/or via direct interventions via the stray cat population, e.g. by trapping stray cats and keeping them alive or killing them (Janeczko, 2020; Kennedy et al., 2020; Loyd and Miller, 2010; Palmer, 2006; Robertson, n.d.). In some countries, the legislation promotes the protection of stray cats at national level by establishing the so-called "feline colonies", whose healthcare must be guaranteed by the Local Veterinary Services, while their daily needs are entrusted to the municipalities, through voluntary staff (Voslářová and Passantino, 2012).

Involving volunteers and residents in interventions to manage cat populations is important for changing or creating behaviours that might help to reduce the problem. Motivation is a central tenet of behaviour change theories (Deci and Ryan, 2008; Michie et al., 2011). Alongside capability and opportunity in the COM-B model, motivation is recognised as being automatic (controlled by emotions and impulses) or reflective (driven by evaluative thought) (Michie et al., 2011). Empowering individuals to engage in projects can enable behaviour change (Goodman et al., 1998). Empowerment is an enabling process and is motivational because outcomes of empowerment include individuals in communities taking control over their environments and organizing to find solutions to problems (Garvin and Cox, 2001; Rappapon, 2008). When an individual feels in control, motivation for behaviours can become autonomous which creates stable adoption of behaviours and therefore a more reflective approach, rather than one controlled by emotion or impulse (Deci and Ryan, 2008).

As citizens may protest against stray cat policy decisions it is important for policy makers to understand public opinion on possible stray cat population management scenarios within the existing legal options and which factors influence these opinions (Deak et al., 2019; Lohr and Lepczyk, 2014). Acceptance of cat management scenarios by the public will differ between stray cat management scenarios and according to personal preference of inhabitants, and may also evolve over time (Rand et al., 2019a; Wolf and Schaffner, 2019). Knowing opinions of different citizens to guide decision making, within the options available according to Animal Protection Laws, is key to developing and finding common ground for a supported policy (Loyd and Hernandez, 2012; McLeod et al., 2019; Van Patter et al., 2019a; Wald et al., 2013).

Existing research on attitudes in humans towards stray cat population management shows that attitudes are influenced by different factors, such as attitude towards cats (loving cats or not having an affiliation with cats) (Bjerke and Østdahl, 2004), owning a cat (Kuhne, 2019; Lord, 2008), gender (Finkler and Terkel, 2012), age (Loyd and Miller, 2010), level of education (Peterson et al., 2012), area of residence (Gramza et al., 2016; Lord, 2008; Loyd and Hernandez, 2012; Uetake et al., 2014), whether children are present in the household (Welsh et al., 2014), and religion (Davey et al., 2020). Also the impact of habitat on stray cats and how stray cats themselves live in it, can influence the acceptance of certain management scenarios (Gramza et al., 2016; Soulsbury and White, 2015). While there is already some research on above-mentioned factors, to our knowledge no multivariate data mining has been performed on a large dataset for audience segmentation. This is needed to get a better grasp and insight on the underlying factors for (non-)acceptance of stray cat management interventions (Kay et al., 2017). Grouping people based on shared characteristics, in our research taking into account socio-demographic and geographic variables, makes it easier to develop tailored interventions and communication on stray cat control.

The aims of this study were twofold: (i) to acquire insight on the acceptance of or opposition against seven stray cat population management scenarios and (ii) to discern socio-demographic factors that influence the acceptance of these management scenarios. Our hypotheses were:

- Respondents will prefer management scenarios that allow stray cats to continue to live and that improve the living situation of the stray cats to the ones that involve killing cats or not taking action.

- The factors age, area of residence, attitudes towards cats, cat ownership, gender, level of education and whether or not a respondent has children will affect the likelihood of acceptance or rejection of the different management scenarios.

We used Flanders (Belgium) as an example. With a population density of 485 inhabitants per $\mathrm{km}^{2}$ (Studiedienst van de Vlaamse Regering, 2016), Flanders can be described as a highly urbanized region with urban, peri-urban and rural parts. In 2018, Flanders also installed a new legislation on owners' responsibilities towards their cats and cities' liability towards stray cats (Besluit van de Vlaamse Regering van 23 
februari 2018). The important features of this legislation for our study were that household cats need to be neutered before the age of five months and veterinarians need to register the neutered cats in an by the government created database. Concerning stray cats, the cities are responsible for the control of nuisance caused by the stray cats on their territory. Therefore, they have to set up a contact point where residents can report nuisance from stray cats. Furthermore, they have to implement a plan in order to control the nuisance from stray cats with the most animal-friendly methods available. In addition, the legislation stipulates that when stray cats are released again, the council shall ensure that the cats are neutered, fed in a controlled way and have sufficient shelter, if possible in consultation with the neighbours.

\section{Materials and methods}

\subsection{Survey design}

The questionnaire used for this study was developed based on discussions with experts (veterinarians, government, municipal administrators and statisticians). Also, some questions from the survey of the Bulwell Cat Watch Project in the UK were used (McDonald et al., 2018). The survey was tested on a pilot audience of 10 researchers and nonprofessionals belonging to Ghent University and our own network. This resulted in the rewording of some questions to assure clarity.

The final questionnaire comprised three sections relating to attitudes and socio-demographic characteristics: (i) a section on attitudes towards cats (loving cats or not) and cat ownership, (ii) a section on acceptance of management interventions and (iii) a section on socio-demographic characteristics. In total, there were twenty-six closed questions, of which fourteen were reported in this paper.

Section (i) consisted of two closed questions on whether the respondent was a cat-lover and owned (a) cat(s).

Section (ii) contained seven closed questions (one for each management strategy), gauging acceptance of the strategy, using a 6-point Likert scale ranging from 1 (totally agree) to 5 (totally disagree), with 3 indicating a neutral response and 6 no opinion. The proposed management strategies were:

Three household cat (HC) management options (indirect intervention):

- Compulsory neutering of all household cats (that are not registered for breeding) with support provided for the owner through financial interventions from the city / municipality / government (HC-NES)

- Compulsory neutering of all household cats (that are not registered for breeding) without support for the owner provided through financial interventions from the city / municipality / government (HC-NEN)

- Encouraging responsible cat ownership education (e.g. by organizing public awareness campaigns that increase knowledge about household cats' needs and behaviour) (HC-FRO)

Three stray cat (SC) management options (direct intervention):

- Increasing the number of stray cats that are trapped and taken to shelters for adoption (SC-SHE)

- Increasing the number of stray cats that are trapped, neutered and assigned to a cat colony managed by a local caregiver (Trap Neuter Return: TNR) (for which food, shelter and minimal care are provided) (SC-COC)

- Increasing the number of stray cats that are trapped and killed (SCKIL)

And:

- Not undertaking any action (NOI)
Section (iii) had five closed questions about age of the respondent, area of residence, level of education, gender and whether the respondent had children or not.

Based on scientific literature and research findings, it was clear that there was a need for standardized and shared definitions in order to be able to use information from other studies (Jaroš, 2018; Robertson, n.d.; Slater, 2007, 2004). Definitions on three cat sub-populations (household, colony/community and stray cat), three areas (rural/urban/periurban) and seven management interventions were clarified in the questionnaire (Miller et al., 2014; Sparkes et al., 2013). A copy of the questionnaire and definitions are available in Dutch and English from the senior author upon request, see supplementary file 2 .

\subsection{Data collection}

A web-based survey was conducted between February 19, 2018 and July 30, 2018 using an online questionnaire designed with Google Forms. The target population were adults ( $>18$ years) from the general population in Flanders. A call for survey participation was launched via websites of Flemish cities, municipalities, shelters, wildlife and pet organisations, network mailings, Twitter and Facebook. Since we expected a response bias from women, cat lovers, and cat owners, we made it explicit that we were also looking for men, non-cat lovers and non-cat owners. Based on findings that cats and dogs are less likely to be in a same household, the most popular dog magazine in Flanders was invited to publish an announcement for the survey (Murray et al., 2010). All technical and organizational measures were taken to secure the privacy of the data conforming to the GDPR and Ghent university data management regulations.

\subsection{Statistical analysis}

The proportions of Agreement (A; "totally agree" and "agree" combined), Neutral (N; "neutral" and "no opinion" combined) and Disagreement (D; "disagree" and "totally disagree" combined) were compared across the different management scenarios using the twosample z-test. All $p$-values were adjusted for multiplicity using the Bonferroni method. R statistical software was used (R Core Team, 2018).

The relationships between each management scenario and the potentially influencing factors were investigated using the Chi-square test statistic with important associations being considered as those with p-values $<0.05$. CHAID (CHi-squared Automatic Interaction Detection) analysis was used to gain insights on the factors (and their interactions) that influence respondents' opinions about stray cat management interventions (Kass, 1980). The output of the CHAID analysis is summarized in a tree with splitting factors (variables ranked based on the p-values of the Chi-square test statistic) that has a hierarchical structure with (terminal) nodes. The following demographic characteristics were selected as independent variables: age, area of residence, attitude towards cats, cat ownership, level of education, gender, and having children or not. The factors representing whether or not respondents loved cats (attitudes towards cats) and whether or not they owned cats were also included. A separate CHAID analysis was performed for each management scenario. All analyses were done using the CHAID package in the R statistical software (R Core Team, 2018).

Respondents were grouped into six age groups: (1) 18-24, (2) 25-34, (3) 35-44, (4) 45-54, (5) 55-64, (6) $65 \geq$ (Carey, 2003; Poresky and Daniels, 1998). For the purpose of the analysis, we grouped scores 1 and 2 into "agree", scores 4 and 5 into "disagree", and 3 and 6 were grouped as "neutral".

\section{Results}

\subsection{Descriptive statistics}

A total of 4453 people filled out the questionnaire completely. After 
excluding data from respondents not living in Flanders $(n=287)$, being younger than $18(n=100)$ and from double entries $(n=7)), 4059$ complete entries were further analysed. Respondents could skip a question if they did not want to answer the specific question, which explains the small differences in number of answers per question (see Annex Table). Despite our efforts to balance the population of respondents, the majority were cat lovers $(94.6 \%)$, cat owners $(77.1 \%)$, women (84.4\%) and respondents without children (65.1\%). A small majority of respondents had at least an undergraduate degree (60.9\%). Respondent age ranged from 13 to 87 years; after leaving out the respondents younger than 18 we had following age distribution: 18-24 (14.2\%), 25-34 (27.3\%), 35-44 (20.9\%), 45-54 (19.5\%), 55-64 $(12.5 \%), 65 \leq(5.6 \%)$. Among cat owners, $37 \%$ had a single cat, and $63 \%$ two or more. The distribution of respondents according to area of residence was: rural (18.6\%), urban (39.1\%), and peri-urban $(42.2 \%)$ (See supplementary file 3 ).

Respondents agreed most (89.9\%) and disagreed (3.9\%) least with the management intervention that involved fostering responsible household cat ownership, followed by the conversion of stray cats into colony/community cats (Table 1 ). On the other hand, respondents disagreed most with the scenarios in which cats were killed $(86.7 \%)$ or no action was undertaken (87.3\%). These were also the scenarios with which respondents agreed the least, with the NOI strategy getting the least number of respondents to agree (3.3\%). There was no significant difference between the proportions of respondents who agreed with the HC-NES and SC-SHE strategies.

\subsection{Factors influencing opinions on management scenarios}

We applied CHAID decisions trees to further analyse the dataset, in order to identify and visually illustrate combinations of factors leading to opinions. This facilitated the interpretation of the effects of selected factors and their interactions on each of these management scenarios (Table 2). Five management options had five splitting factors (HC-NES, HC-NEN, HC-FRO, SC-COC and SC-KIL), one had four (NOI) and there was one management option with only one (SC-SHE). Attitudes towards cats appeared four times as the strongest predicting variable for opinion on management scenarios (for HC-NES, HC-NEN, SC-COC and SC-KIL), area of residence turned out two times as most important predicting factor (for HC-FRO and SC-SHE) and gender once (NOI). Cat ownership only showed three times up as a splitting factor in the different CHAIDS analysis and with a small effect (for HC-NES, HC-NEN and SC-KIL). The factor gender came forth six times as a second important factor and level of education and (not) having children twice as a second important

Table 1

Distribution of responses (\%) towards different stray cat population management options.

\begin{tabular}{lllll}
\hline & $\begin{array}{l}\% \text { of } \\
\text { Agree }\end{array}$ & $\begin{array}{l}\% \text { of } \\
\text { Neutral }\end{array}$ & $\begin{array}{l}\text { \% of } \\
\text { Disagree }\end{array}$ & $\begin{array}{l}\text { Total number of } \\
\text { responses }\end{array}$ \\
\hline $\begin{array}{l}\text { Household cat } \\
\text { management options }\end{array}$ & & & & \\
HC-NES & $61.4^{\mathrm{a}}$ & $13.5^{\mathrm{a}}$ & $25.1^{\mathrm{a}}$ & 3984 \\
HC-NEN & $45.7^{\mathrm{b}}$ & $16.9^{\mathrm{b}}$ & $37.4^{\mathrm{b}}$ & 3976 \\
HC-FRO & $89.9^{c}$ & $6.1^{\mathrm{c}}$ & $3.9^{\mathrm{c}}$ & 3939 \\
Stray cat management & & & & \\
options & & & & \\
SC-SHE & $61.0^{\mathrm{a}}$ & $19.6^{\mathrm{d}}$ & $19.4^{\mathrm{d}}$ & 3899 \\
SC-COC & $76.3^{d}$ & $12.4^{a}$ & $11.3^{e}$ & 3907 \\
SC-KIL & $7.7^{e}$ & $5.6^{c}$ & $86.7^{f}$ & 4017 \\
No intervention (NOI) & $3.3^{f}$ & $9.4^{a}$ & $87.3^{f}$ & 3953 \\
\hline
\end{tabular}

HC = house cat, SC = stray cat; NES = Neutering with support; NEN = Neutering without support, FRO = Fostering responsible ownership, SHE = Shelter uptake, $\mathrm{COC}=$ Colony cat conversion, $\mathrm{KIL}=$ Kill, NOI $=$ No intervention.

Different superscript letters (a-f) within a column indicate significant $(P<0: 05)$ differences.

The italic indicates management options with highest and lowest acceptance. factor, age only appeared once as a second important factor.

We report CHAID details for the three management scenarios with striking different outcomes on (dis)agreement: HC-NEN, SC-COC and SC-KIL. The other four management scenarios CHAIDS - HC-NES, HCFRO, SC-SHE and NOI - had no remarkable factor variations to highlight, and can be found in supplementary file 1 .

\subsubsection{Compulsory neutering of household cats without financial support (HC-NEN)}

A tree with five factors and eight terminal nodes was generated by the CHAID analysis illustrated in Fig. 1. All factors included in the analysis were important except for age and area of residence. A big difference on agreeing is seen in the branch of those who do not love cats or are neutral in the second split between respondents who had (no) children and the factor cat ownership. Those who had one or two cats disagreed most with the scenario ( $>70 \%)$. Almost the same outcome is seen for those respondents who love cats a lot, went to Primary school or preferred not to say and were men or X. Men who loved cats a lot, had Primary education or PNS disagreed much more than like women did with this scenario.

\subsubsection{Increase conversion of stray cats to colony cats (SC-COC)}

The CHAID analysis generated a tree with seven splitting factors (branches) and ten terminal nodes illustrated in Fig. 2. A striking result is that female respondents tended to agree in all splits more than men do with this scenario. Also noteworthy is that in the group who do not love cats or are indifferent to them no second predicting factor was found and there are just slightly more respondents who disagreed than agreed with this scenario $(\sim 40 \%)$.

\subsubsection{Increase in the number of stray cats that are killed (SC-KIL)}

For the scenario 'Increase in the number of stray cats that are killed', the CHAID analysis generated a tree with eight branches and ten terminal nodes, illustrated in Fig. 3. Overall, most respondents tended to disagree with this management scenario. There is one notable exception; men who do not love cats or are indifferent to cats and have zero or four or more cats agreed with this scenario $(>60 \%)$, whereas in all the other terminal nodes the disagree proportion was the biggest.

\section{Discussion}

Cities and municipalities can adopt interventions targeting household cats as a (indirect) way of controlling stray cat populations or stray cats as a (direct) way of controlling them. They can also adopt a combined strategy. Considering that cities and municipalities need to manage stray cat populations and that legislation may offer several options with varying impact on the cats, it is important to assess citizens' attitudes towards management options and to identify factors influencing those attitudes in order to develop a customized approach. We have described and analysed the data of 4059 web-survey respondents in Flanders on this subject, which is to our knowledge the largest such study to date using multivariate data mining.

Based on the amount of female respondents in our survey (84.4\%) and our difficulty to reach male respondents to fill out the survey gender has to be taken into account when targeting the citizens for assessment, awareness, education or communication purposes on stray cat management. In the study of Murray et al. (2010) cats were more likely to be owned by female respondents. Women as the biggest group of respondents on cat issues was also the case in the research of Gunaseelan et al. (2013), Hall et al. (2016) Peek et al. (1997), Rand et al. (2019a, 2019b) and Wald et al. (2013). Toukhsati et al. (2007) sees as a trend in the high proportion of female respondents in attitude research on animal welfare issues. Based on our results and other research we might conclude that women may be more emotionally involved and interested in responding to issues on cat management (Selby and Rhoades, 1981). 
Table 2

Predicting weight of the seven variables for opinion on the seven management options in CHAID decision tree.

\begin{tabular}{|c|c|c|c|c|c|c|c|}
\hline $\begin{array}{l}\text { Management scenario/factor appearance in } \\
\text { CHAID }\end{array}$ & Gender & Age & Cat ownership & Area of residence & $\begin{array}{l}\text { Having } \\
\text { children }\end{array}$ & Education & $\begin{array}{l}\text { Attitude towards } \\
\text { cats }\end{array}$ \\
\hline HC-NES & & ++ & +++ & + & ++++ & & +++++ \\
\hline HC-NEN & +++ & & +++ & & ++++ & ++++ & +++++ \\
\hline HC-FRO & ++++ & & & +++++ & +++ & $\begin{array}{l}++++ \\
2 *+++\end{array}$ & ++ \\
\hline SC-SHE & & & & +++++ & & & \\
\hline SC-COC & $2 *++++$ & +++ & & &,+++++ & +++ & +++++ \\
\hline SC-KIL & $3 *++++$ &,+++++ & +++ & & +++ & & +++++ \\
\hline NOI & +++++ & ++++ & & & & ++ & +++ \\
\hline Number of times factor appeared in all CHAIDS & 8 & 5 & 3 & 3 & 6 & 6 & 6 \\
\hline Number of times first ranked factor & 1 & & & 2 & & & 4 \\
\hline Number of times second ranked factor & 6 & 1 & & & 2 & 2 & \\
\hline Number of times third ranked factor & 1 & 2 & 3 & & 3 & 3 & 1 \\
\hline
\end{tabular}

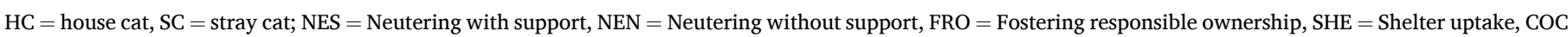
$=$ Colony cat conversion, $\mathrm{KIL}=$ Kill, NOI $=$ No intervention.

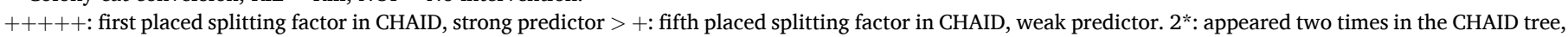

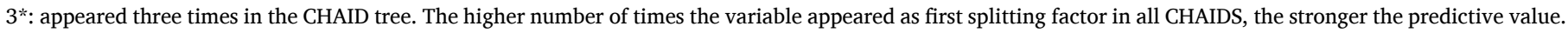

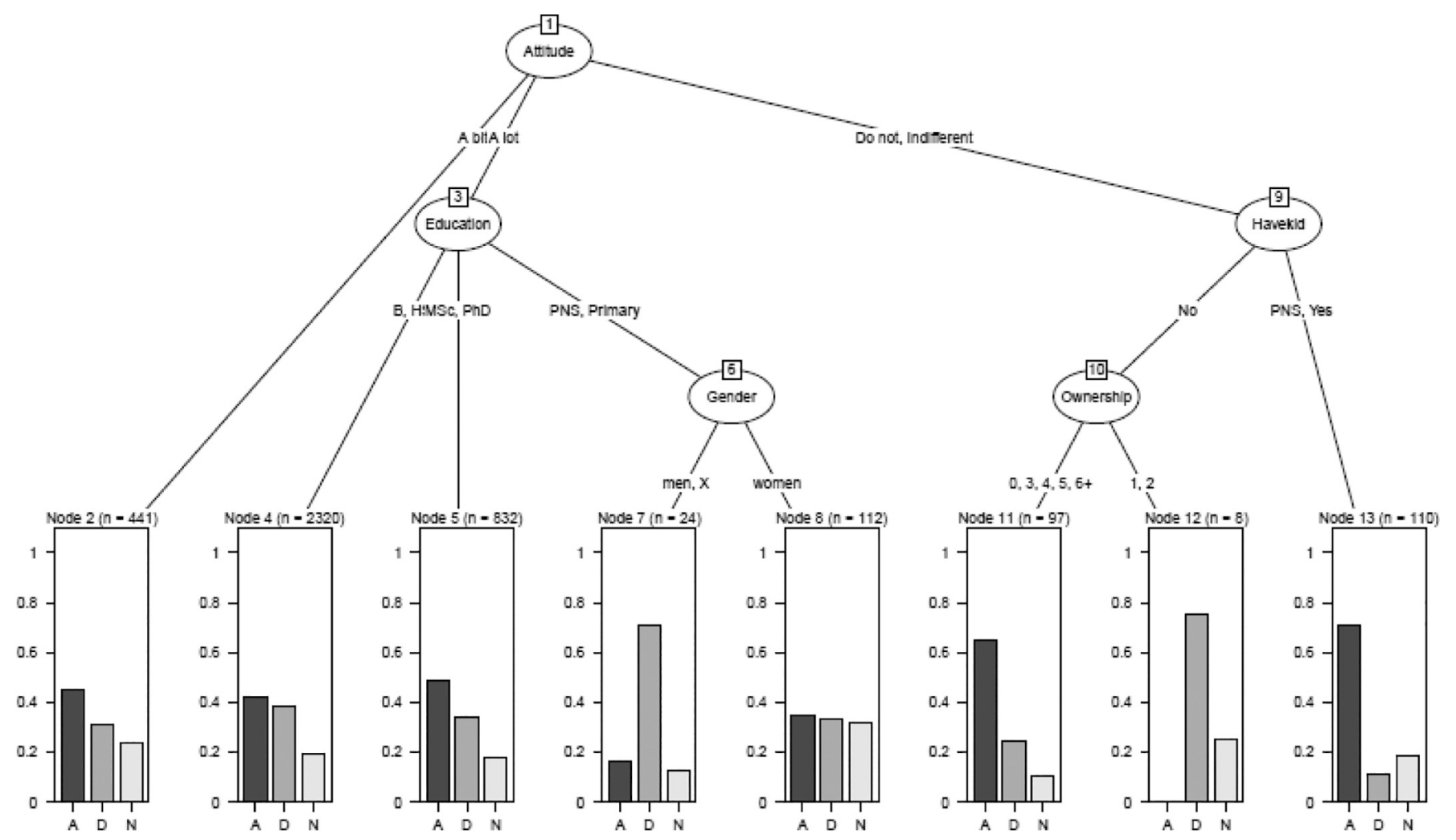

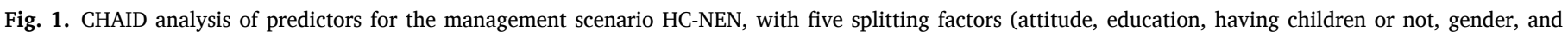
whether the respondent owns a cat) and eight terminal nodes, showing the proportion of respondents who agree (A), disagree (D) or are neutral (N).

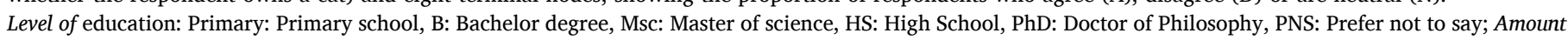
of owned household cats: (0) zero cats, (1) one cat, (2) 2 cats, (3) 3 cats, (4) 4 cats, (5) 5 cats, (6+) 6 or more cats.

In our study a small majority of respondents (60.9\%) had at least an undergraduate degree which aligns with the study of Rand et al. (2019a, 2019b) and the majority of cat owners kept two or more cats, which aligns with the study of Strickler and Shull (2013). All things considered, the demographic characteristics indicate that the respondents in the current study were representative of other findings concerning participation in research on attitudes towards cats, cat management and animal welfare. It is important for cities and municipalities to take into account that if they conduct a survey on the management of stray cats on their territory, they will likely have a similar population of respondents (see limitations). There may be slight differences if an area is either very disadvantaged or very affluent or entirely urban/rural. This would also be in line with the influence of the size of the stray animal problem on people's attitudes towards cats (National Cat Centre, 2020). Our respondents group may be similar to other surveys on cat issues, but the results are probably not representative of the general population.

\subsection{Respondent's opinions on seven stray cat management options}

Our results supported our hypothesis that stray cat management scenarios that allow cats to continue to live and that improve the health and welfare for the cats were preferred over those where the cats will be killed or no action is taken, which is in line with the research findings from Van Patter et al. (2019a, 2019b). These preferences are explained 


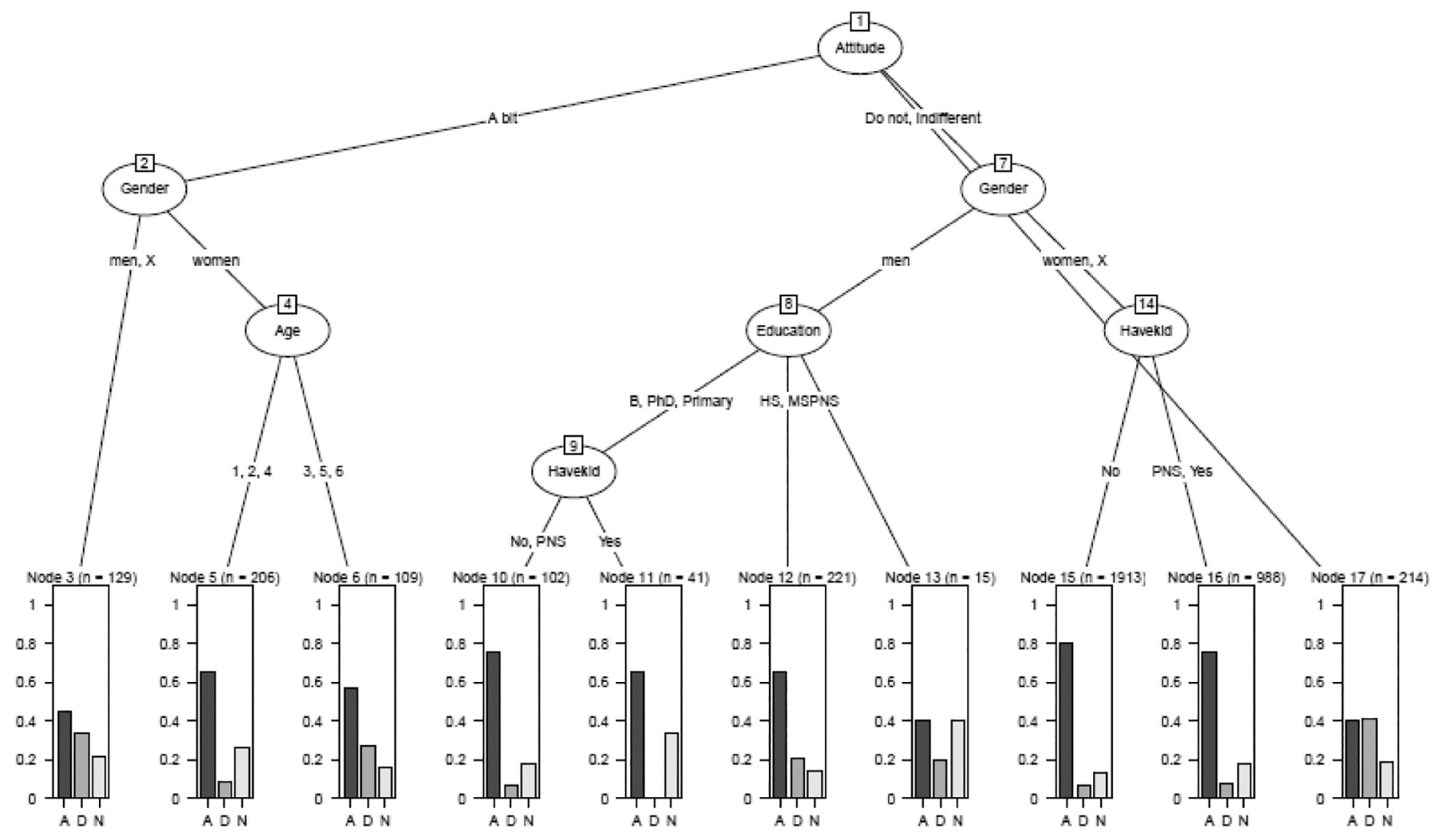

Fig. 2. CHAID analysis of predictors for the management scenario SC-COC, with seven splitting factors (attitude towards cats, gender (twice), education, having children (twice) or not and age) and ten terminal nodes, showing the proportion of respondents who agree (A), disagree (D) or are neutral (N).

Level of education: Primary: Primary school, B: Bachelor degree, Msc: Master of science, HS: High School, PhD: Doctor of Philosophy, PNS: Prefer not to say; Age: (1) 19-24, (2) 25-34, (3) 35-44, (4) 45-54, (5) 55-64, (6) $65 \geq$.

by Wolf and Schaffner (2019) as a shift in ethics over time, whereby the recognition of the intrinsic value of non-human animals and our moral obligation to treat them with compassion comes more and more into the foreground in stray cat management. Several authors describe the rise of animal welfare concerns in stray cat management interventions as an element at stake that cannot be ignored (Davey and Zhao, 2020; Gilhofer et al., 2019; Wolf and Hamilton, 2020).

There was a clear preference for the scenario of focusing on HC-FRO, it was the most agreed upon (89.9\% agreed, 3.9\% disagreed and 6.1\% were neutral). Fostering responsible ownership was defined as "encouraging responsible cat-ownership in order to have less abandonment of household cats by organizing public awareness campaigns that increase knowledge about household cats' needs and behaviour". Our finding that the respondents favoured the scenario HC-FRO supports the conclusion of the need for education in other studies (Finkler and Terkel, 2012; Lohr and Lepczyk, 2014; Loyd and Hernandez, 2012; Rand et al., 2019b; Robertson, 2008; Slater et al., 2008; Van Patter et al., 2019a; Welsh et al., 2014). Educational campaigns and targeted publicity can serve to reduce the overpopulation problem, as attitudes and behaviours related to overpopulation (e.g. abandonment and reproductive capacity) were indeed shown to be affected by knowledge and education (Finkler and Terkel, 2012; Gibson et al., 2002; Kay et al., 2017; Kuhne, 2019; Loyd and Hernandez, 2012; Toukhsati et al., 2007; Van Patter et al., 2019a; Welsh et al., 2014). Also here it can be questioned if one-size-fitsall education is the right way, education should be tailored too, given the data in our study and findings in the field of education (CAST, 2018; Gunaseelan et al., 2013; Jacobetty et al., 2019; Murray et al., 2015). Health authorities, governments, veterinary practitioners, shelters, NGO's and animal welfare practitioners can all target household cat owners in order to promote responsible cat ownership (Carvelli et al., 2016; Finkler and Terkel, 2012; Prata, 2020). Also researching what people understand as responsible ownership is important as Westgarth et al. (2019) described: we need to understand how well household cat owners understand their cats' behavioral, welfare, and basic care needs (Delgado and Reevy, 2018).

The other indirect household cat management scenario that more than half of the respondents agreed with was neutering with financial support for the owner. This is important as any changes achieved in knowledge and attitudes can only be followed through with behaviour change if people have the capability and opportunity (Michie et al., 2011). Therefore, interventions such as financial support are vital for those on low income. Our results showed that fewer respondents agreed and more disagreed with compulsory neutering without support. With $37.4 \%$ of the respondents disagreeing on HC-NEN it had the third highest rate of disagreement (after NOI and SC-KIL), and had the second highest proportion of respondents being neutral. Based on the CHAID analysis we identified a striking similarity on disagreeing, more specifically between those who do not love cats or are neutral, had no children and owned 1 or 2 cats and those who loved cats a lot, had primary school education or preferred not to say and were men or X, both terminal nodes show that around $70 \%$ disagreed. These outcomes contrast the other six terminal nodes.

For the direct management scenarios there was substantial acceptance, SC-COC (89.9\%) and SC-SHE (76.3\%) were most agreed upon. The SC-COC scenario was described as "Increase in the number of stray cats that are caught, neutered and assigned to a managed cat colony" and the SC-SHE scenario as "Increase in the number of stray cats that are caught and taken to shelters". Our findings of preference align with the findings of Loyd and Hernandez (2012), Van Patter et al. (2019a) and Wolf and Hamilton (2020). These results clearly underline the shift in ethics as described by Wolf and Schaffner (2019). The difference between the two scores can be explained by the fact that in the SC-COC scenario the stray cats are managed, for their own welfare, in their original environment. In the scenario SC-SHE the dilemma is that most 


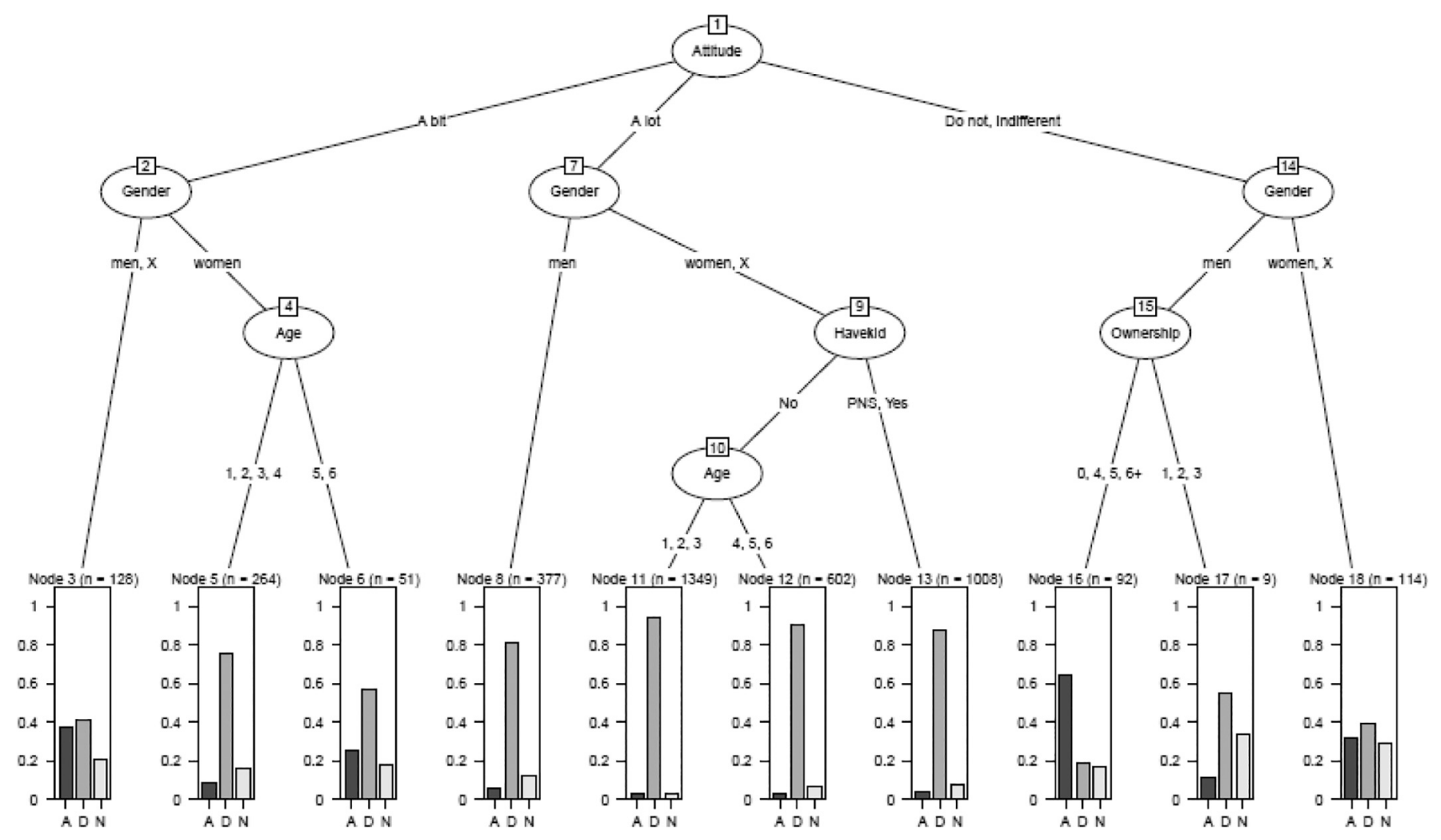

Fig. 3. CHAID analysis of predictors for the management scenario SC-KIL, with eight splitting factors and ten terminal nodes, showing the proportion of respondents who agree (A), disagree (D) or are neutral (N).

Opinion: A: Agree, D: Disagree, N: Neutral; Level of education: Primary: Primary school, B: Bachelor degree, Msc: Master of science, HS: High School, PhD: Doctor of Philosophy, PNS: Prefer not to say; Amount of owned household cats: (0) zero cats, (1) one cat, (2) 2 cats, (3) 3 cats, (4) 4 cats, (5) 5 cats, (6+) 6 or more cats; Age: (1) 19-24, (2) 25-34, (3) 35-44, (4) 45-54, (5) 55-64, (6) $65 \geq$.

of the stray cats are too unsocialized to be adopted and therefore trusting them to shelters would be contrary to their welfare (Crawford and Fleming, 2019; Davey and Zhao, 2020; National Cat Centre, 2020). The CHAID analysis showed that only respondents who were indifferent to cats or do not like cats, disagreed slightly more than agreed with the SCSHE scenario. Seeking out the current caregivers in communities and embracing them in participatory policy design can have an important impact on the welfare of the stray cats, the acceptance of the neighbourhood for managed cat colonies and for the management of wildlife (Mitsui et al., 2020). Creation of certified caregivers, training and education of caregivers are therefore pivotal. Trapping methods; best practices for feeding (preventing overfeeding, keeping the feeding places clean) and monitoring (reporting ill or new arrived cats) are part of their management task (Finkler and Terkel, 2011; Gilhofer et al., 2019; Natoli et al., 1999; Toukhsati et al., 2007; Zito et al., 2015). Besides these caregiving duties, certified caregivers can also raise public awareness and report issues on management for governments to deal with. In terms of behaviour change, they can also model good cat management behaviours to other residents (Carvelli et al., 2016; Finkler and Terkel, 2011; Peterson et al., 2020). If a city or municipality opts to formalise community managed cat colony places, it is important to communicate with the neighbours before starting and it is recommended that the management is based on community engagement in order to be sustainable (Gilhofer et al., 2019; McDonald et al., 2018; Mcdonald and Clements, 2019; Spehar and Wolf, 2020; Zito et al., 2015). Bringing communities together on issues so that they feel they have some ownership of projects and initiatives is also important for effecting normative beliefs. The idea that peers and important others approve of any behavioral change is critical to enabling change to happen (Ajzen, 1991). In this way, some social cohesion can be created; a sense of relatedness, which provides for the social opportunity element of COM-B and basic needs theory for behaviour change (Deci and Ryan, 2008; Michie et al., 2011). Furthermore the presence of locally managed cats in (peri-)urban areas also gives inhabitants the opportunity to connect locally and directly with animals (Davey and Zhao, 2020; Rand et al., 2019a; Soulsbury and White, 2015; Spehar and Wolf, 2020).

Of the direct interventions SC-KIL is least supported (7.7\% agreed) which is consistent with the results of the research of Dabritz et al. (2006) and Wald et al. (2013) and affirms the findings of (Wolf and Schaffner, 2019). The CHAID analysis showed one deviant result, men who did not like cats or were indifferent to them and had 0 or $\geq 4$ cats agreed $(>60 \%)$ with the SC-KIL scenario. We demonstrated that the view of the respondents on doing nothing is not an option. NOI had the lowest acceptance score of all management scenarios (3.3\% agreed, 87.3\% disagreed and $9.4 \%$ were neutral) which aligns with other research (Lohr and Lepczyk, 2014; Van Patter et al., 2019a). According to Lohr and Lepczyk (2014) SC-KIL is preferred over NOI because killing a stray cat is perceived as more humane than leaving the cat on its own in its environment.

\subsection{Predicting factors}

McLeod et al. (2019, 2017) and Rand et al. (2019b) raised attention to audience segmentation as being important for implementing stray cat management programs and for adequate communication on it. Our findings revealed that there are three decisive factors affecting opinions towards the cat management scenarios (in descending order): 'attitude towards cats', 'area of residence' and 'gender'. 'Having children' and 'education' were less strong predicting factors and only started appearing in second splits. We have shown that 'age' is a low predicting factor and 'cat ownership' is almost negligible as a predictor. Based on our literature research we think further research is needed on the effect 
of 'area of residence', ' having children' and 'education' (Dickinson et al., 2010; Van Patter et al., 2019a) as results of other research are sometimes scarce and conflicting and hence allow little understanding of them until now (Endenburg and Knol, 1977; Healy, 2000; Pisa, 2018; Read, 2019).

That 'attitude towards cats' is an important factor was also found by Uetake et al. (2014). The difference with 'cat ownership' is striking in our CHAID outcomes where 'attitude towards cats' (four times first splitting factor) and 'cat ownership' (three times third splitting factor) have divergent predictive values. As research shows not all cat lovers keep cats due to different reasons, e.g. rented accommodation (not allowed to have pets), too small housed, family composition (not the only one in the household to decide on whether having pets, a family member having allergies) or illness. This could clarify why 'attitude towards cats' is a far more stable predictor than 'cat ownership' (Casey et al., 2009; Jensen et al., 2020; Scarlett et al., 1999). Conversely, having a cat in the house can also be not one's own choice, but a family member's and thus not necessarily imply a positive attitude towards cats.

Urban and peri-urban grouped twice as a main factor, once in the indirect scenario HC-FRO and once in the direct scenario SC-SHE, which aligns with other research where 'area of residence' was found an important predictor for acceptance of management scenarios (Lord, 2008; Wilken, 2012). The human population density and abundance of stray cats in urban/peri-urban areas is generally higher (Liberg and Sandell, 2000; Miller et al., 2014), which brings about other issues than in rural settings. Degrees of nuisance between areas are different and depend on different factors (Uetake et al., 2014). Also the habitat composition of the area plays a role on different levels (Lord, 2008). For example type of habitat influences cat behaviour and survival rates, Gramza calls it the 'bidirectional risks concept' (2016), which also implies different interactions with humans, as described by Miller et al. (2014). Human-wildlife interactions differ between areas (Finkler et al., 2011a; Soulsbury and White, 2015) and proximity to stray cat populations could be influential in acceptance for management scenarios as Wilken suggests (2012). Endemic biodiversity and proximity to significant ecological areas was also found an important factor for acceptance of management scenarios (Bassett et al., 2020; Hall et al., 2016; Mameno et al., 2017). Although stray cats are sometimes perceived themselves as pests, depending on the habitat, stray cats can serve as pest control themselves in different areas (Bonacic et al., 2019; Mahlaba et al., 2017; Parsons et al., 2018). All of these elements can clarify the importance of the factor. In our study, 'area of residence' was five times a decisive factor in the CHAIDS, which together with above mentioned research makes the predictive value of 'area of residence' noteworthy and subject to further research as different subfactors can play a role in areas of residence. Understanding the dynamics of these subfactors is challenging due to often complex behaviours and habitats (Dickman, 2010). Taking into account the characteristics of the inhabitants and the habitat of the area of residence is complex but crucial for effective stray cat policy (Lord, 2008; Mameno et al., 2017). All these variables play a role in designing policies, targeting communication and creating public awareness (Deak et al., 2019; Finkler et al., 2011b; Flockhart et al., 2016). As Crowley et al. (2020) states: the dual status of the species as both wild predator and domestic companion underpins different interaction with and nuisance for humans.

Age of respondent had almost no impact on the preference of the different cat management scenarios which aligns with findings of Signal and Taylor (2007) and Wilken (2012) who found that age did not affect respondent preference. Based on their findings and those of this study, age may not be a reliable predictor for stray cat management preference. However, this does not align with other research on TNR such as the study of Loyd and Miller (2009) who found that predictors of preference for TNR management were age, gender, and support for wildlife rights.

In line with the research of Lord (2008), Loyd and Hernandez (2012), Peterson et al. (2012) and Rand et al. (2019b) gender had an effect on respondent's opinions. Gender appeared eight times in the CHAID's as a splitting factor, we could thus conclude that this variable has some predictive value. It should also be noted that the majority of colony caretakers are women (Gunther et al., 2016; Loyd and Miller, 2010; Peterson et al., 2012; Zasloff and Hart, 1998). In the Cat Watch studies, it was found that caretakers are utmost important to target (Mcdonald and Clements, 2019). However, it cannot be overrated compared to the factors 'attitude towards cats' and 'area of residence'. This confirms some findings in the paper of Herzog (Herzog, 2007) in which he sets out that gender cannot be seen as a stable predictor.

In our survey, having children was two times a second placed splitting factor in the CHAID's analyses. There is almost no research on having children as a decisive factor in acceptance of stray cat management interventions, which makes it a possible future avenue for research (Blouin, 2012). We found no strong predicting factor in education which contradicts the findings of the study of Kuhne (2019). Cat ownership was a weak factor in HC-NES, HC-NEN and SC-KIL, which aligns with the findings of Lord (2008).

Our findings together with above mentioned research findings underline the need for every stray cat policy to be customized to human characteristics and area of residence. Characteristics and understanding of the inhabitants of the targeted area should definitely be considered (Crowley et al., 2020; Gramza et al., 2016; Kennedy et al., 2020). Concerning the area of residence it is important is to make sure that the policy that will be implemented is allowed (e.g. national law and local regulations) and that the level of effectiveness of the policies implemented up till then in the area (including NOI) are taken into account. Stray cat managers should be well aware of this.

The findings of our study can be used to understand public opinion and find common ground on how to control growth of stray cat populations. This will help (local) governments and (local) managers to make choices and implement these scenarios as stated by Loyd and Hernandez (2012), and McLeod et al. (2019, 2017). The findings could also guide communication on the policy and its implementations from the outset, which would support inhabitants accepting the chosen strategies as well help residents to cooperate with local governments.

\subsection{Limitations}

Study limitations include a lack of information collected from nonrespondents in order to assess possible non-respondent bias (Gunaseelan et al., 2013; Loyd and Hernandez, 2012). Some selection bias may occur as a result of using an online survey. As with other surveys our sample is subject to self-selection bias (Bethlehem, 2010; Khazaal et al., 2014). Furthermore, internet is not so commonly used by older residents and thus may limit access to older respondents, which could explain the lower percentage of respondents over 65 . Also cross-sectional surveys based on age groupings may report age effects that may in actuality reflect cohort effects and not age effects (Poresky and Daniels, 1998). Gender seems to be one of the strongest predictors for Web survey participation with several studies showing that males are less likely to participate than females (Keusch, 2015). Lots of respondents liked cats a lot and were female which is part of self-selecting bias also found in the studies of Groves et al. (2004), Lord (2008) and Kuhne (2019).

A limitation of quantitative analyses of surveys in studying humananimal relationships is that they oversimplify complex factors and reasoning on issues. Although we are aware of the concerns of other researchers that question the use of surveys and underlying methodological assumptions to find out opinions on management methods (Hiby et al., 2017; Teel and Manfredo, 2010; Wald et al., 2013), we do think that the used methodology and research results can be helpful in developing customized stray cat policies.

\section{Conclusion}

The aim of the study was twofold: (i) to look at what the acceptance 
is of seven stray cat population management scenarios and (ii) to discern what factors determine preferences towards these scenarios, using Flanders as an example. Our results show that the majority of respondents in our sample (which consisted mainly of females, cat-lovers, and families without children) are supportive of fostering responsible household cat ownership and creating "cat colonies". However, it should be kept in mind that community engagement is more than just engagement; it should support and empower in order to increase people's confidence and motivation to enable behaviour change. Outcomes have illuminated that the characteristics 'attitude towards cats', 'area of residence' and 'gender' have predictive value for the acceptance of the seven management scenarios. We observed that further research is needed on the effect of 'area of residence', 'having children' and 'education'. Our findings emphasise the value of substantiating public policy decisions on local adequate information on residents and area-specific information. Cities implementing strategies will benefit from audience segmentation and deliberative decision-making. Consideration of possible (non-)acceptance of management interventions will support the success of outreach efforts. Moreover, measuring previous actions and current outcomes to assess the effectiveness of the used strategies and communication should allow for modification where needed. We conclude that strategies should be tailored to each city concerned with sustainable management of local cat populations.

Our research results indicate broad support for a multi-faceted approach in Flanders by which on the one hand, for indirect management, the current level of knowledge among household cat owners regarding cats' behaviour and needs (e.g. behaviour, reproductive capacity...) is improved and one the other hand, for direct management, formalised "cat colonies" are established. Not intervening or killing of stray cats has no public support anymore. These findings are in line with the new Flemish legislation on household cat neutering and registering, and the responsibility of cities to manage the neutered stray cats. Based on our findings we can conclude that present Flemish legislation aligns at this moment with the preferences of the surveyed Flemish residents.

\section{Acknowledgements}

The authors are grateful to all survey respondents who took part. Without their participation, this research would not have been possible.

We wish to thank Tiny De Keuster for sharing her expertise on the survey topic. In addition, Ulrike Tewes for her help in spreading the word on the subject and feeding back the input from FECAVA members.

We gratefully acknowledge the financial support of Dienst Dierenwelzijn from Flanders. This research is an outcome of research efforts supported by FIRE (Fostering Innovative Research based on Evidence) and the POPCAT consortium.

\section{Appendix A. Supplementary data}

Supplementary data to this article can be found online at https://doi. org/10.1016/j.rvsc.2021.02.025.

\section{References}

Aguilar, G.D., Farnworth, M.J., 2013. Distribution characteristics of unmanaged cat colonies over a 20 year period in Auckland, New Zealand. Appl. Geogr. 37, 160-167. https://doi.org/10.1016/J.APGEOG.2012.11.009.

Ajzen, I., 1991. The theory of planned behavior. Organ. Behav. Hum. Decis. Process. 50, 179-211. https://doi.org/10.1016/0749-5978(91)90020-T.

Bassett, I.E., McNaughton, E.J., Plank, G.D., Stanley, M.C., 2020. Cat ownership and proximity to significant ecological areas influence attitudes towards cat impacts and management practices. Environ. Manag. 66, 30-41. https://doi.org/10.1007/ s00267-020-01289-2.

Bethlehem, J., 2010. Selection bias in web surveys. Int. Stat. Rev. 78, 161-188. https:// doi.org/10.1111/j.1751-5823.2010.00112.x.

Bjerke, T., Østdahl, T., 2004. Animal-related attitudes and activities in an urban population. Anthrozoos. https://doi.org/10.2752/089279304786991783.

Blouin, D.D., 2012. Understanding relations between people and their pets. Sociol. Compass 6, 856-869. https://doi.org/10.1111/j.1751-9020.2012.00494.x.
Bonacic, C., Almuna, R., Ibarra, J.T., 2019. Biodiversity conservation requires management of feral domestic animals. Trends Ecol. Evol. https://doi.org/10.1016/ j.tree.2019.05.002.

Calver, M.C., Crawford, H.M., Fleming, P.A., 2020. Response to Wolf et al.: furthering debate over the suitability of trap-neuter-return for stray cat management. Animals 10, 362. https://doi.org/10.3390/ani10020362.

Carey, J.R., 2003. Life span: a conceptual overview. Popul. Dev. Rev. Vol. 29 (S), 1-18.

Carvelli, A., Iacoponi, F., Scaramozzino, P., 2016. A cross-sectional survey to estimate the cat population and ownership profiles in a semirural area of central Italy. Biomed. Res. Int. 2016. https://doi.org/10.1155/2016/3796872.

Casey, R.A., Vandenbussche, S., Bradshaw, J.W.S., Roberts, M.A., 2009. Reasons for relinquishment and return of domestic cats (Felis silvestris catus) to rescue shelters in the UK. Anthrozoos 22, 347-358. https://doi.org/10.2752/ 089279309X12538695316185.

CAST, 2018. Universal Design for Learning Guidelines Version 2.2 [WWW Document]. URL. http://udlguidelines.cast.org/ (accessed 10.31.20).

Crawford, Calver, Fleming, 2019. A case of letting the cat out of the bag-why trapneuter-return is not an ethical solution for stray cat (Felis catus) management. Animals 9, 171. https://doi.org/10.3390/ani9040171.

Crowley, S.L., Cecchetti, M., McDonald, R.A., 2020. Our wild companions: domestic cats in the Anthropocene. Trends Ecol. Evol. https://doi.org/10.1016/j tree.2020.01.008.

Dabritz, H.A., Atwill, E.R., Gardner, I.A., Miller, M.A., Conrad, P.A., 2006. Outdoor fecal deposition by free-roaming cats and attitudes of cat owners and nonowners toward stray pets, wildlife, and water pollution. J. Am. Vet. Med. Assoc. 229, 74-81. https:// doi.org/10.2460/javma.229.1.74.

Dalla Villa, P., Migliaccio, P., Innocenti, I., Nardoia, M., Lafiandra, D.C., 2019. Companion animals welfare in non-epidemic emergencies: the case of Central Italy, post-earthquake 2016/2017. J. Appl. Anim. Ethics Res. 1, 253-279. https://doi.org/ 10.1163/25889567-12340012.

Davey, G., Zhao, X., 2020. Free-roaming cat (Felis catus) management and welfare policies in two university campuses in Beirut, Lebanon: strengths, weaknesses, and opportunities. J. Appl. Anim. Welf. Sci. 23, 41-53. https://doi.org/10.1080/ 10888705.2018.1550721.

Davey, G., Zhao, X., Khor, M.M., 2020. Heterogeneity in beliefs about feeding stray animals: the complexity of human-animal interaction. Hum. Dimens. Wildl. 25 100-103. https://doi.org/10.1080/10871209.2019.1692099.

Deak, B.P., Ostendorf, B., Taggart, D.A., Peacock, D.E., Bardsley, D.K., 2019. The significance of social perceptions in implementing successful feral cat management strategies: a global review. Animals 9, 617. https://doi.org/10.3390/ani9090617.

Deci, E.L., Ryan, R.M., 2008. Self-determination theory: a macrotheory of human motivation, development, and health. In: Canadian Psychology, pp. 182-185. https://doi.org/10.1037/a0012801.

Delgado, M.M., Reevy, G.M., 2018. Development and psychometric evaluation of the cat care and needs scale (CCANS). Anthrozoos 31, 89-100. https://doi.org/10.1080/ 08927936.2018.1406203.

Dickinson, J.L., Zuckerberg, B., Bonter, D.N., 2010. Citizen science as an ecological research tool: challenges and benefits. Annu. Rev. Ecol. Evol. Syst. 41, 149-172. https://doi.org/10.1146/annurev-ecolsys-102209-144636.

Dickman, A.J., 2010. Complexities of conflict: the importance of considering social factors for effectively resolving human-wildlife conflict. Anim. Conserv. 13, 458-466. https://doi.org/10.1111/J.1469-1795.2010.00368.X@10.1111/(ISSN) 1469-1795.CONFLICTS.

Downes, M.J., Dean, R.S., Stavisky, J.H., Adams, V.J., Grindlay, D.J.C., Brennan, M.L., 2013. Methods used to estimate the size of the owned cat and dog population: a systematic review. BMC Vet. Res. 9. https://doi.org/10.1186/1746-6148-9-121.

Endenburg, N., Knol, B.W., 1977. Veterinary Quarterly Behavioural, Household, and Social Problems Associated with Companion Animals: Opinions of Owners and Nonowners, pp. 271-303. https://doi.org/10.1080/01652176.1994.9694434.

Finkler, H., Terkel, J., 2011. Dichotomy in the emotional approaches of caretakers of free-roaming cats in urban feeding groups: findings from in-depth interviews. Anthrozoos 24, 203-218. https://doi.org/10.2752/175303711X12998632257413.

Finkler, H., Terkel, J., 2012. The contribution of cat owners' attitudes and behaviours to the free-roaming cat overpopulation in Tel Aviv, Israel. Prev. Vet. Med. 104, 125-135. https://doi.org/10.1016/J.PREVETMED.2011.11.006.

Finkler, H., Hatna, E., Terkel, J., 2011a. The influence of neighbourhood sociodemographic factors on densities of free-roaming cat populations in an urban ecosystem in Israel. Wildl. Res. 38, 235. https://doi.org/10.1071/WR10215.

Finkler, H., Hatna, E., Terkel, J., 2011b. The impact of anthropogenic factors on the behavior, reproduction, management and welfare of urban, free-roaming cat populations. Anthrozoos 24, 31-49. https://doi.org/10.2752/ 175303711 X12923300467320.

Flockhart, D.T.T., Norris, D.R., Coe, J.B., 2016. Predicting free-roaming cat population densities in urban areas. Anim. Conserv. 19, 472-483. https://doi.org/10.1111/ acv.12264.

Garvin, C.D., Cox, F.M., 2001. A history of community organizing since the civil war with special reference to oppressed communities. In: Rothman, J., Elrich, J.L., Tropman, J.E., Rothman, J., Erlich, J.L. (Eds.), Strategies of Community Intervention. Peacock Publishers, Belmont, CA, pp. 65-100.

Gibson, K.L., Keizer, K., Golding, C., 2002. A trap, neuter, and release program for feral cats on Prince Edward Island. Can. Vet. J. 43, 695-698.

Gilhofer, E.M., Windschnurer, I., Troxler, J., Heizmann, V., 2019. Welfare of feral cats and potential influencing factors. J. Vet. Behav. 30, 114-123. https://doi.org/ 10.1016/j.jveb.2018.12.012.

Goodman, R.M., Speers, M.A., McLeroy, K., Fawcett, S., Kegler, M., Parker, E., Smith, S. R., Sterling, T.D., Wallerstein, N., 1998. Identifying and defining the dimensions of 
community capacity to provide a basis for measurement. Health Educ. Behav. https://doi.org/10.1177/109019819802500303.

Gramza, A., Teel, T., VandeWoude, S., Crooks, K., 2016. Understanding public perceptions of risk regarding outdoor pet cats to inform conservation action. Conserv. Biol. 30, 276-286. https://doi.org/10.1111/cobi.12631.

Groves, R.M., Presser, S., Dipko, S., 2004. The role of topic interest in survey participation decisions. Public Opin. Q. 68, 2-31. https://doi.org/10.1093/poq/ nfh002.

Gunaseelan, S., Coleman, G.J., Toukhsati, S.R., 2013. Attitudes toward responsible pet ownership behaviors in Singaporean cat owners. Anthrozoos 26, 199-211. https:// doi.org/10.2752/175303713X13636846944123.

Gunther, I., Raz, T., Berke, O., Klement, E., 2015. Nuisances and welfare of free-roaming cats in urban settings and their association with cat reproduction. Prev. Vet. Med. 119, 203-210. https://doi.org/10.1016/J.PREVETMED.2015.02.012.

Gunther, I., Raz, T., Even Zor, Y., Bachowski, Y., Klement, E., 2016. Feeders of freeroaming cats: personal characteristics, feeding practices, and data on cat health and welfare in an urban setting of Israel. Front. Vet. Sci. 3 https://doi.org/10.3389/ fvets.2016.00021.

Gunther, I., Raz, T., Klement, E., 2018. Association of neutering with health and welfare of urban free-roaming cat population in Israel, during 2012-2014. Prev. Vet. Med. 157, 26-33. https://doi.org/10.1016/j.prevetmed.2018.05.018.

Hall, C.M., Adams, N.A., Bradley, J.S., Bryant, K.A., Davis, A.A., Dickman, C.R., Fujita, T., Kobayashi, S., Lepczyk, C.A., McBride, E.A., Pollock, K.H., Styles, I.M., van Heezik, Y., Wang, F., Calver, M.C., 2016. Community attitudes and practices of urban residents regarding predation by pet cats on wildlife: an international comparison. PLoS One 11, e0151962. https://doi.org/10.1371/journal. pone. 0151962.

Healy, B., 2000. Love Thy Neighbour. ASNSW Avic. Rev.

Herzog, H.A., 2007. Gender differences in human-animal interactions: a review. Anthrozoos. https://doi.org/10.2752/089279307780216687.

Hiby, E., Atema, K.N., Brimley, R., Hammond-Seaman, A., Jones, M., Rowan, A., Fogelberg, E., Kennedy, M., Balaram, D., Nel, L., Cleaveland, S., Hampson, K. Townsend, S., Lembo, T., Rooney, N., Whay, H.R., Pritchard, J., Murray, J., van Dijk, L., Waran, N., Bacon, H., Knobel, D., Tasker, L., Baker, C., Hiby, L., 2017. Scoping review of indicators and methods of measurement used to evaluate the impact of dog population management interventions. BMC Vet. Res. 13, 1-20. https://doi.org/10.1186/s12917-017-1051-2.

Høgåsen, H.R., Er, C., Di Nardo, A., Dalla Villa, P., 2013. Free-roaming dog populations: a cost-benefit model for different management options, applied to Abruzzo, Italy. Prev. Vet. Med. 112, 401-413. https://doi.org/10.1016/j.prevetmed.2013.07.010.

International Cat Care, 2018. International Declaration of Responsibilities to Cats 12

Jacobetty, R., Lopes, D., Fatjó, J., Bowen, J., Rodrigues, D.L., 2019. Psychological correlates of attitudes toward pet relinquishment and of actual pet relinquishment: the role of pragmatism and obligation. Animals 10, 63. https://doi.org/10.3390/ ani10010063.

Janeczko, S., 2020. Community Cats, in: High-Quality, High-Volume Spay and Neuter and Other Shelter Surgeries. Wiley, pp. 477-508. https://doi.org/10.1002/ 9781119646006.ch25.

Jaroš, F., 2018. Cat cultures and threefold modelling of human-animal interactions: on the example of Estonian cat shelters. Biosemiotics 11, 365-386. https://doi.org/ 10.1007/s12304-018-9332-0.

Jensen, J.B.H., Sandøe, P., Nielsen, S.S., 2020. Owner-related reasons matter more than behavioural problems - a study of why owners relinquished dogs and cats to a Danish animal shelter from 1996 to 2017. Animals 10, 1064. https://doi.org/ 10.3390/ani10061064.

Kass, G.V., 1980. An exploratory technique for investigating large quantities of categorical data. Appl. Stat. 29, 119. https://doi.org/10.2307/2986296.

Kay, A., Coe, J.B., Pearl, D., Young, I., 2017. A scoping review of published research on the population dynamics and control practices of companion animals. Prev. Vet. Med. 144, 40-52. https://doi.org/10.1016/j.prevetmed.2017.05.006.

Kennedy, B.P.A., Cumming, B., Brown, W.Y., 2020. Global strategies for population management of domestic cats (Felis catus): a systematic review to inform best practice management for remote indigenous communities in Australia. Animals 10, 663. https://doi.org/10.3390/ani10040663.

Keusch, F., 2015. Why do people participate in Web surveys? Applying survey participation theory to Internet survey data collection. Manag. Rev. Q. 65, 183-216. https://doi.org/10.1007/s11301-014-0111-y.

Khazaal, Y., Van Singer, M., Chatton, A., Achab, S., Zullino, D., Rothen, S., Khan, R., Billieux, J., Thorens, G., 2014. Does self-selection affect samples'representativenes in online surveys an investigation in online video game research. J. Med. Internet Res. 16. https://doi.org/10.2196/jmir.2759.

Kuhne, F., 2019. Cat owners: how they keep and care for their own cats and their attitudes to stray and feral cats in Germany. Anim. Vet. Sci. 7, 24. https://doi.org/ 10.11648/j.avs.20190701.14.

Liberg, O., Sandell, M., 2000. Density, spatial organisation and reproductive tactics in the domestic cat and other felids. In: The Domestic Cat: The Biology of Its Behaviour, pp. 83-98.

Lohr, C.A., Lepczyk, C.A., 2014. Desires and management preferences of stakeholders regarding feral cats in the Hawaiian Islands. Conserv. Biol. 28, 392-403. https://doi. org/10.1111/cobi.12201.

Lord, L.K., 2008. Attitudes toward and perceptions of free-roaming cats among individuals living in Ohio. J. Am. Vet. Med. Assoc. 232, 1159-1167. https://doi.org/ 10.2460/javma.232.8.1159.

Loyd, K.A.T., Hernandez, S.M., 2012. Public perceptions of domestic cats and preferences for feral cat management in the southeastern United States. Anthrozoos 25, 337-351. https://doi.org/10.2752/175303712X13403555186299.
Loyd, K.A., Miller, C.A., 2009. Factors related to preferences for trap-neuter-release management of feral cats among Illinois homeowners. J. Wildl. Manag. 74, 160-165. https://doi.org/10.2193/2008-488.

Loyd, K.A.T., Miller, C.A., 2010. Influence of demographics, experience and value orientations on preferences for lethal management of feral cats. Hum. Dimens. Wildl. 15, 262-273. https://doi.org/10.1080/10871209.2010.491846.

Mahlaba, T.A.M., Monadjem, A., McCleery, R., Belmain, S.R., 2017. Domestic cats and dogs create a landscape of fear for pest rodents around rural homesteads. PLoS One 12. https://doi.org/10.1371/journal.pone.0171593.

Mameno, K., Kubo, T., Suzuki, M., 2017. Social challenges of spatial planning for outdoor cat management in Amami Oshima Island, Japan. Glob. Ecol. Conserv. 10, 184-193. https://doi.org/10.1016/j.gecco.2017.03.007.

Mcdonald, J.L., Clements, J., 2019. Engaging with socio-economically disadvantaged communities and their cats: human behaviour change for animal and human benefit. Animals 9, 175. https://doi.org/10.3390/ani9040175.

McDonald, J.L., Farnworth, M.J., Clements, J., 2018. Integrating trap-neuter-return campaigns into a social framework: developing long-term positive behavior change toward unowned cats in urban areas. Front. Vet. Sci. 5, 258. https://doi.org/ 10.3389/fvets.2018.00258.

McLeod, L.J., Hine, D.W., Bengsen, A.J., Driver, A.B., 2017. Assessing the impact of different persuasive messages on the intentions and behaviour of cat owners: a randomised control trial. Prev. Vet. Med. 146, 136-142. https://doi.org/10.1016/j. prevetmed.2017.08.005.

McLeod, L.J., Hine, D.W., Driver, A.B., 2019. Change the humans first: principles for improving the management of free-roaming cats. Animals 9, 555. https://doi.org/ 10.3390/ani9080555.

Michie, S., van Stralen, M.M., West, R., 2011. The behaviour change wheel: a new method for characterising and designing behaviour change interventions. Implement. Sci. 6, 42. https://doi.org/10.1186/1748-5908-6-42.

Miller, P.S., Boone, J.D., Briggs, J.R., Lawler, D.F., Levy, J.K., Nutter, F.B., Slater, M., Zawistowski, S., 2014. Simulating free-roaming cat population management options in open demographic environments. PLoS One 9, e113553. https://doi.org/ 10.1371/journal.pone.0113553.

Mitsui, K., Sato, S., Kakuma, Y., 2020. Effects of the community cats program on population control, migration and welfare status of free-roaming cats in Tokyo, Japan. Animals 10. https://doi.org/10.3390/ani10030461.

Murray, J.K., Browne, W.J., Roberts, M.A., Whitmarsh, A., Gruffydd-Jones, T.J., 2010. Number and ownership profiles of cats and dogs in the UK. Vet. Rec. 166, 163-168. https://doi.org/10.1136/vr.b4712.

Murray, J.K., Mosteller, J.R., Loberg, J.M., Andersson, M., Benka, V.A.W., 2015. Methods of fertility control in cats: owner, breeder and veterinarian behavior and attitudes. J. Feline Med. Surg. https://doi.org/10.1177/1098612X15594994.

National Cat Centre, 2020. Cat Watch: Report to Stakeholders 2019. Haywards Heath.

Natoli, E., Ferrari, M., Bolletti, E., Pontier, D., 1999. Relationships between cat lovers and feral cats in Rome. Anthrozoos. https://doi.org/10.2752/ 089279399787000408 .

Natoli, E., Maragliano, L., Cariola, G., Faini, A., Bonanni, R., Cafazzo, S., Fantini, C., 2006. Management of feral domestic cats in the urban environment of Rome (Italy). Prev. Vet. Med. 77, 180-185. https://doi.org/10.1016/j.prevetmed.2006.06.005.

Natoli, E., Ziegler, N., Dufau, A., Pinto Teixeira, M., 2019. Unowned free-roaming domestic cats: reflection of animal welfare and ethical aspects in animal laws in six European countries. J. Appl. Anim. Ethics Res. 2, 38-56. https://doi.org/10.1163/ 25889567-12340017.

Palmer, C., 2006. Killing Animals in Animal Shelters, in: Killing Animals.

Parsons, M.H., Banks, P.B., Deutsch, M.A., Munshi-South, J., 2018. Temporal and spaceuse changes by rats in response to predation by feral cats in an urban ecosystem. Front. Ecol. Evol. 6, 146. https://doi.org/10.3389/fevo.2018.00146.

Peek, C.W., Dunham, C.C., Dietz, B.E., 1997. Gender, relational role orientation, and affinity for animal rights. Sex Roles 37, 905-920.

Peterson, M.N., Hartis, B., Rodriguez, S., Green, M., Lepczyk, C.A., 2012. Opinions from the front lines of cat colony management conflict. PLoS One 7, e44616. https://doi, org/10.1371/journal.pone.0044616.

Peterson, M.N., Serenari, C., Rodriguez, S.L., Lee Jenni, G.D., 2020. Comparing personalities of self-identified cat colony caretakers and bird conservation professionals. Hum. Dimens. Wildl. 25, 296-299. https://doi.org/10.1080/ 10871209.2020.1716113.

Pisa, R., 2018. Co-Existing with Wildlife: A Meta-Review of Factors Influencing citizen's Attitudes Towards Urban Wildlife.

Poresky, R.H., Daniels, A.M., 1998. Demographics of pet presence and attachment. Anthrozoos 11, 236-241. https://doi.org/10.2752/089279398787000508.

Prata, J.C., 2020. Strategies for the improvement of pet health and welfare in Portugal based on a pilot survey on husbandry, opinion, and information needs. Animals 10, 848. https://doi.org/10.3390/ani10050848.

R Core Team, 2018. R: A Language and Environment for Statistical Computing.

Rand, J., Fisher, G., Lamb, K., Hayward, A., 2019a. Public opinions on strategies for managing stray cats and predictors of opposition to trap-neuter and return in Brisbane, Australia. Front. Vet. Sci. 5, 290. https://doi.org/10.3389/ fvets. 2018.00290.

Rand, J., Hayward, A., Tan, K., 2019b. Cat colony caretakers' perceptions of support and opposition to TNR. Front. Vet. Sci. 6, 57. https://doi.org/10.3389/fvets.2019.00057. Rappapon, J., 2008. Studies in Empowerment. https://doi.org/10.1300/J293V03N02_ 02.

Read, J., 2019. Among the Pigeons: Why Our Cats Belong Indoors. Wakefield Press.

Robertson, S.A., 2008. A review of feral cat control. J. Feline Med. Surg. 10, 366-375. https://doi.org/10.1016/j.jfms.2007.08.003. 
Robertson BVMS, S.A., n.d. A Review of Feral Cat Control. doi:https://doi.org/10.1016 j.jfms.2007.08.003.

Scarlett, J.M., Salman, M.D., New Jr., J.G., Kass, P.H., 1999. Reasons for relinquishment of companion animals in U.S. animal shelters: selected health and personal issues. J. Appl. Anim. Welf. Sci. 2, 41-57. https://doi.org/10.1207/s15327604jaws020144.

Selby, Lloyd A., Rhoades, J.D., 1981. Attitudes of the public towards dogs and cats as companion animals. J. Small Anim. Pract. 22, 129-137. https://doi.org/10.1111/ j.1748-5827.1981.tb00592.x.

Signal, T.D., Taylor, N., 2007. Attitude to animals and empathy: comparing animal protection and general community samples. Anthrozoos 20, 125-130. https://doi. org/10.2752/175303707X207918.

Slater, M.R., 2004. Understanding issues and solutions for unowned, free-roaming cat populations. In: Journal of the American Veterinary Medical Association, pp. 1350-1354. https://doi.org/10.2460/javma.2004.225.1350.1.

Slater, M.R., 2007. The Welfare of Feral Cats.

Slater, M.R., Di Nardo, A., Pediconi, O., Villa, P.D., Candeloro, L., Alessandrini, B., Del Papa, S., 2008. Free-roaming dogs and cats in central Italy: public perceptions of the problem. Prev. Vet. Med. 84, 27-47. https://doi.org/10.1016/J. PREVETMED.2007.10.002.

Soulsbury, C.D., White, P.C.L., 2015. Human-Wildlife Interactions in Urban Areas: A Review of Conflicts, Benefits and Opportunities. BIOONE.

Sparkes, A.H., Bessant, C., Cope, K., Ellis, S.L., Finka, L., Halls, V., Hiestand, K., Horsford, K., Laurence, C., MacFarlaine, I., Neville, P.F., Stavisky, J., Yeates, J., Isfm, 2013. ISFM guidelines on population management and welfare of unowned domestic cats (Felis catus). J. Feline Med. Surg. 15, 811-817. https://doi.org/10.1177/ $1098612 X 13500431$.

Spehar, D.D., Wolf, P.J., 2020. The impact of return-to-field and targeted trap-neuterreturn on feline intake and euthanasia at a municipal animal shelter in Jefferson county, Kentucky. Animals 10, 1-18. https://doi.org/10.3390/ani10081395.

Stavisky, J., 2014. Too many cats: how owner beliefs contribute to overpopulation. Vet Rec. 174, 116-117. https://doi.org/10.1136/vr.g1100.

Stavisky, J., Brennan, M.L., Downes, M., Dean, R., 2012. Demographics and economic burden of un-owned cats and dogs in the UK: results of a 2010 census. BMC Vet. Res. 8, 163. https://doi.org/10.1186/1746-6148-8-163.

Strickler, B.L., Shull, E.A., 2013. An owner survey of toys, activities, and behavior problems in indoor cats. J. Vet. Behav. Clin. Appl. Res. 9, 207-214. https://doi.org/ 10.1016/j.jveb.2014.06.005.

Studiedienst van de Vlaamse Regering, 2016. Vlaanderen in cijfers.

Teel, T.L., Manfredo, M.J., 2010. Understanding the diversity of public interests in wildlife conservation. Conserv. Biol. 24, 128-139. https://doi.org/10.1111/j.15231739.2009.01374.x.
The European Parliament's Intergroup on the Welfare and Conservation of Animals, 2016. New Eurobarometer on Attitudes of Europeans towards Animal Welfare [WWW Document]. URL. https://www.animalwelfareintergroup.eu/2016/03/16/ new-eurobarometer-on-attitudes-of-europeans-towards-animal-welfare/.

Toukhsati, S.R., Bennett, P.C., Coleman, G.J., 2007. Behaviors and attitudes towards semi-owned cats. Anthrozoos 20, 131-142. https://doi.org/10.2752/ $175606707 \times 207927$.

Uetake, K., Yamada, S., Yano, M., Tanaka, T., 2014. A survey of attitudes of local citizens of a residential area toward urban stray cats in Japan. J. Appl. Anim. Welf. Sci. 17, 172-177. https://doi.org/10.1080/10888705.2013.798558.

Van Patter, L., Flockhart, T., Coe, J., Berke, O., Goller, R., Hovorka, A., Bateman, S., 2019a. Perceptions of community cats and preferences for their management in Guelph, Ontario. Part I: a quantitative analysis. Can. Vet. J. 60 (1), 41-47.

Van Patter, L., Flockhart, T., Coe, J., Berke, O., Goller, R., Hovorka, A., Bateman, S., 2019b. Perceptions of community cats and preferences for their management in Guelph, Ontario. Part II: A qualitative analysis. Can. Vet. J. 60, 48-54.

Voslářová, E., Passantino, A., 2012. Stray dog and cat laws and enforcement in Czech Republic and in Italy. Ann. Ist. Super. Sanita. https://doi.org/10.4415/ann_12_01 16.

Wald, D.M., Jacobson, S.K., Levy, J.K., 2013. Outdoor cats: identifying differences between stakeholder beliefs, perceived impacts, risk and management. Biol. Conserv. 167, 414-424. https://doi.org/10.1016/J.BIOCON.2013.07.034.

Welsh, C.P., Gruffydd-Jones, T.J., Roberts, M.A., Murray, J.K., 2014. Poor owner knowledge of feline reproduction contributes to the high proportion of accidental litters born to UK pet cats. Vet. Rec. 174, 118. https://doi.org/10.1136/vr.101909.

Westgarth, C., Christley, R.M., Marvin, G., Perkins, E., 2019. The responsible dog owner: the construction of responsibility. Anthrozoos 32, 631-646. https://doi.org/ 10.1080/08927936.2019.1645506.

Wilken, R.L.M., 2012. Feral Cat Management: Perceptions and Preferences (A Case Study). ProQuest Diss. Theses. https://doi.org/10.31979/etd.nf6m-mjpc.

Wolf, P.J., Hamilton, F., 2020. Managing free-roaming cats in U.S. cities: an object lesson in public policy and citizen action. J. Urban Aff. https://doi.org/10.1080/ 07352166.2020 .1742577$.

Wolf, P.J., Schaffner, J.E., 2019. The road to TNR: examining trap-neuter-return through the lens of our evolving ethics. Front. Vet. Sci. 5 https://doi.org/10.3389/ fvets.2018.00341.

Zasloff, R.L., Hart, L.A., 1998. Attitudes and care practices of cat caretakers in Hawaii. Anthrozoos 11, 242-248. https://doi.org/10.2752/089279398787000599.

Zito, S., Vankan, D., Bennett, P., Paterson, M., Phillips, C.J.C., 2015. Cat ownership perception and caretaking explored in an internet survey of people associated with cats. PLoS One 10, e0133293. https://doi.org/10.1371/journal.pone.0133293. 